\title{
How To Get Your Clinical Teaching Team Ready For Curriculum Change: A Practical Guide
}

This article was published in the following Dove Press journal:

Advances in Medical Education and Practice

\author{
Lindsay Bank ${ }^{1,2}$ \\ Mariëlle Jippes ${ }^{3}$ \\ Albert JJA Scherpbier (D) ${ }^{4}$ \\ Corry den Rooyen (iD) \\ Fedde Scheele ${ }^{1,2,6}$ \\ 'Department of Healthcare Education, \\ OLVG Hospital, Amsterdam, the \\ Netherlands; ${ }^{2}$ Faculty of Earth and Life \\ Sciences, Athena Institute for \\ Transdisciplinary Research, VU \\ University, Amsterdam, the Netherlands; \\ ${ }^{3}$ Department of Plastic Surgery, Erasmus \\ Medical Center, Rotterdam, the \\ Netherlands; ${ }^{4}$ Faculty of Health, Medicine \\ and Life Sciences, School of Health \\ Professions Education, Maastricht \\ University, Maastricht, the Netherlands; \\ ${ }^{5}$ Movation BV, Maarssen, the \\ Netherlands; ${ }^{6}$ School of Medical Sciences, \\ Institute for Education and Training, \\ Amsterdam University Medical Centre, \\ Amsterdam, the Netherlands
}

Correspondence: Lindsay Bank

Department of Education, OLVG

Hospital, Jan Tooropstraat I64,

Amsterdam 106I AE, the Netherlands

Tel +3I205108292

Email bank.lindsay@gmail.com

\begin{abstract}
Our health care system is constantly adapting to change at an increasingly rapid pace. Unavoidably, this also applies to the field of medical education. As a result, clinical teaching teams face the challenging task of successfully implementing the proposed changes in daily practice. It goes without saying that implementing change takes time and that you need to be patient. However, a successful change process needs more than that. Change models or strategies could offer a helping hand. The questionnaire Specialty training's Organizational Readiness for curriculum Change (STORC) is a tool aiming to do just that. With a focus on readiness for change, this questionnaire tries to support implementation efforts in PGME. Additionally, since change is a team effort, it focusses on clinical teaching teams particularly. In this paper, we offer a practical guide for clinical teaching teams on how to deal with any concerns or hurdles detected in any of the core elements of readiness for change, in order to smoothen and support the educational change processes these teams are confronted with.
\end{abstract}

Keywords: change readiness, postgraduate medical education, questionnaire, clinical teaching team, curriculum change, educational change

\section{Introduction}

Our health care system is constantly adapting to change at an increasingly rapid pace. It must deal with new regulations, innovations, scientific progress, social pressures and other factors. Unavoidably, this also has an influence on the field of medical education. Therefore, clinical teaching teams must be adaptive to new developments and face the challenging task to successfully implement the proposed changes. But how? Here, change management strategies could offer a helping hand. However, due to a strong disciplinary divide, this helping hand is rarely sought. ${ }^{1,2}$ Additionally, a lack of knowledge translation is further hampering the integration of new knowledge into daily practice. ${ }^{3,4}$ This is unfortunate, because too little guidance from appropriate change models could slow down change processes, mainly because opportunities for advanced assessment, evaluation and planning are missed..$^{5-8}$ Therefore, it is important to develop tools to bridge the gap between change management and medical education. The questionnaire Specialty Training's Organizational Readiness for curriculum Change (STORC) is a tool aiming to do this. ${ }^{9}$

The questionnaire STORC measures organizational readiness for change (ORC) regarding educational or curriculum change in PGME, or more specifically, within clinical teaching teams. ${ }^{9,10}$ Since this tool was specifically designed for this setting, it has an eye for the active role of trainees in both educational and 
change processes as well as for the different pressures to change that are specific for PGME. ${ }^{9,10}$ Organizational change readiness reflects the degree to which members of an organization, in this case, members of a clinical teaching team (CTT), are collectively motivated and capable to implement change. ${ }^{10}$ Change readiness determines the degree of readiness present and is seen as a critical precursor of successful implementation of complex change initiatives in health care settings. ${ }^{11-13}$ The questionnaire STORC represents the core components of organizational readiness for change. ${ }^{9}$ When ORC is high, team members are more dedicated to contribute to the proposed change and more persevering in the case of setbacks. Conversely, when ORC is low, team members are more likely to consider change as undesirable and may resist participation. ${ }^{5,11,12,14,15}$ Change readiness can be assessed prior or during a change process to diagnose any possible obstacles in the implementation process in order to apply appropriate interventions to improve a team's readiness. Additionally, readiness can be assessed repeatedly to explore the effects of these interventions. ${ }^{10}$

In this paper, we would like to further bridge the gap between change management and medical education as well as between theory and practice by providing a practical guide for all members of clinical teaching teams (CTTs) to help address any concerns or hurdles detected in any of the core elements of readiness for change during their change process. Table 1 shows some examples of hurdles that might hamper implementation processes and how they relate to the specific elements of readiness for change. In practice, a hurdle such as "the lack of urgency is felt", could be the result of generic models of CBME that are not always specifically outlined. This might lead to in a lack of clarity about its content, meaning or relevance. ${ }^{16-18}$ Alternatively, a hurdle such as "lack of management support" could lead back to the complex dynamics of a teaching hospital, in which clinical service and medical education are interrelated and potentially have competing goals. ${ }^{19,20}$

Column 1 shows the subscales of the questionnaire STORC that represent the core elements of organizational readiness for change. Column 2 shows possible hurdles that might hamper the implementation processes corresponding to the core elements of ORC and are related to hurdles described in change management literature. Column 3 presents recommended solutions regarding hurdles related to the corresponding core element of ORC. These recommendations are founded in change management literature as well as literature regarding the diffusion of innovation service organizations.

In this paper, when referred to a clinical teaching team we refer to the different medical specialties that provide specialty training within their own departments in teaching hospitals. The medical doctors in these departments together form a clinical teaching team and are responsible for providing up to standard specialty training programs. A clinical teaching team consists out of a program director, all clinical staff members and all trainees within that department. Additionally, when referred to a local educational board/committee we refer to an educational board consisting out of all program directors within the hospital, educationalists, trainee representatives as well as the board of directors that is present in every teaching hospital in the Netherlands. Among others, this board or committee is responsible for ensuring educational quality, a safe learning climate and mediation in case of a conflict between a trainee and a program director within their own hospital.

\section{Elements Of Readiness For Change Pressure To Change}

Resistance is part of a normal change process as you alter the status quo. ${ }^{21}$ Frustrating as it might be, resistance can lead to better results when it is used as a resource to improve the quality and clarity of the objectives and strategies of a change initiative. By continuously seeking input from your team members, it can help to correct your own biases as well as to engage sceptics in service of a better plan..$^{22,23}$

Program directors are usually the first ones to be confronted with an educational change. The other members of the clinical teaching teams depend on their program director to be properly informed about what is coming. ${ }^{24}$ As a program director it is important to realize that the moment you decide to communicate a change, that change has not been similarly internalized by your colleagues as with you. It is recommended to take time to acknowledge the challenges and to address any concerns or fears colleagues might have. ${ }^{23}$ Provide sufficient information about the innovation and be specific about how this change will affect your colleagues' job. It can be beneficial to consider best practices from other CTTs to help focus on opportunities rather than challenges as well as reduce the perceived complexity of a change. ${ }^{7}$

\section{Appropriateness}

A change addresses a discrepancy between the current state of practice and a desired state of practice. One of 
Table I Overview Of The Elements Of Readiness For Change, Their Possible Hurdles And Recommended Solutions

\begin{tabular}{|c|c|c|}
\hline $\begin{array}{l}\text { Subscale Of STORC } \\
\text { Element Of Readiness }\end{array}$ & Possible Hurdles: & Recommended Solutions \\
\hline Pressure to change & $\begin{array}{l}\ldots \text { are unwilling to adapt old routines and express } \\
\text { discontent about top-down pressure }\end{array}$ & $\begin{array}{l}\text { - Resistance is a form of feedback. Listen and use it. } \\
\text { - Show best practices from other teams to reduce the } \\
\text { perceived complexity of the innovation. } \\
\text { - Provide sufficient information about the innovation and } \\
\text { how it will affect your team. }\end{array}$ \\
\hline Appropriateness & $\begin{array}{l}\ldots \text { express doubts whether the proposed change } \\
\text { will be an appropriate solution for the intended } \\
\text { improvement of practice }\end{array}$ & $\begin{array}{l}\text { - Define, within the team, what the intended meaning of } \\
\text { the innovation is. } \\
\text { - Show the relative advantage of the innovation, eg, by } \\
\text { means of best practices. } \\
\text { - Let team members adapt and refine the innovation on a } \\
\text { limited basis to let it suit their own needs and local } \\
\text { context. }\end{array}$ \\
\hline Necessity to change & ... feel no urgency to change & $\begin{array}{l}\text { - Provide information about the need for change - what } \\
\text { changes in the health care system push this innovation? } \\
\text { - Make the benefits of the innovation clearly visible - eg, } \\
\text { what is its relevance for a trainee's performance? Define } \\
\text { the long-term gains. } \\
\text { - Use strong leadership to help create a receptive con- } \\
\text { text for change. }\end{array}$ \\
\hline $\begin{array}{l}\text { Management support and } \\
\text { leadership }\end{array}$ & ... feel insufficient management support & $\begin{array}{l}\text { - Show that goals of the innovation align with the goals of } \\
\text { the local educational/faculty board or committee. } \\
\text { - Provide a platform for sharing experiences and best } \\
\text { practices. } \\
\text { - Provide outcome measures at an institutional level. }\end{array}$ \\
\hline Staff culture & $\begin{array}{l}\ldots \text { show limited commitment or shared } \\
\text { responsibility within the team }\end{array}$ & $\begin{array}{l}\text { - Link the innovation to the existing knowledge and skills } \\
\text { base of the team members. } \\
\text { - Create short-term goals with and relevant for the team } \\
\text { members. } \\
\text { - Define your team's social network and use it. }\end{array}$ \\
\hline The formal leader & $\begin{array}{l}\ldots \text { do not know who has the final authority to } \\
\text { make decisions regarding the change }\end{array}$ & $\begin{array}{l}\text { - Define clear roles and responsibilities for all team } \\
\text { members. } \\
\text { - Identify different leadership roles and systematically har- } \\
\text { ness the efforts of these leaders. } \\
\text { - Train leaders to lead. }\end{array}$ \\
\hline Involvement & $\begin{array}{l}\ldots \text { express that they feel like their opinion is not } \\
\text { taken into account }\end{array}$ & $\begin{array}{l}\text { - Provide accurate and timely information about the inno- } \\
\text { vation and the implementation process. } \\
\text { - Listen to the crowd, use both formal and informal } \\
\text { communication channels. } \\
\text { - Seek input, respond and continue to do so during the } \\
\text { entire change process. }\end{array}$ \\
\hline
\end{tabular}

(Continued) 
Table I (Continued).

\begin{tabular}{|c|c|c|}
\hline Subscale Of STORC & Possible Hurdles: & Recommended Solutions \\
\hline Project resources & $\begin{array}{l}\ldots \text { express a sense of insecurity about whether } \\
\text { they have the ability/skills to implement the change }\end{array}$ & $\begin{array}{l}\text { - Build on existing expertise. } \\
\text { - Provide sufficient faculty development - related to the } \\
\text { innovation (eg, teaching skills) and the implementation } \\
\text { process (eg, giving feedback). } \\
\text { - Provide support on task issues (eg, how to incorporate } \\
\text { the innovation in daily work). }\end{array}$ \\
\hline Clarity of mission and goals & $\begin{array}{l}\ldots \text { miss a clear vision on where the change will } \\
\text { lead them }\end{array}$ & $\begin{array}{l}\text { - Look for a purposeful construction of a shared vision. } \\
\text { - Get feedback and adjust if necessary. } \\
\text { - Keep it short and inspiring. } \\
\text { - Create clear indicators of successful change and discuss } \\
\text { them in regular team meetings. }\end{array}$ \\
\hline The implementation plan & $\begin{array}{l}\ldots \text { do not know when the change should be } \\
\text { implemented and what consecutive actions to take }\end{array}$ & $\begin{array}{l}\text { - Break the innovation down in manageable parts. } \\
\text { - Provide clear timelines. } \\
\text { - Monitor and evaluate the impact of the innovation. } \\
\text { Adapt if necessary. }\end{array}$ \\
\hline
\end{tabular}

the key sentiments in change processes is the sense that a change is appropriate. In other words, the proposed change is believed to adequately address the discrepancy. ${ }^{25}$ Appropriateness is important because team members might feel change is needed while disagreeing with the specific change that is proposed. Again, best practices might be helpful to visualize the appropriateness of the suggested change. ${ }^{7}$

Furthermore, the meaning of an innovation is usually not fixed but rather socially constructed and therefore can be negotiated or reframed. ${ }^{7,26}$ Thereby, it can be adapted and modified to better fit the needs in the local situation. It is even possible to experiment with a change on a limited basis in order to help you find meaning in a change. This will enable CTTs to emphasize their own strengths and make a change valuable in their local context. ${ }^{7,27}$

\section{Necessity To Change}

In addition to believing a change is appropriate, establishing a sense of urgency is crucial in order to obtain the required cooperation from your team members. The importance of this step is usually underestimated. When urgency is low, it is more difficult to generate sufficient power and credibility to guide the change effort or to convince others to spend the time necessary to create a change vision. ${ }^{13}$
In order to create a sense of urgency, it is important to explain the rationale behind the intended change; ie, what forces drive the innovation. ${ }^{13,22}$ Looking at the current changes in PGME possible forces include the introduction of competency frameworks, new regulations, outcomebased education, a need for more accountability to society, centralization of health care and so on. Furthermore, it is important to provide information about future opportunities and abilities to stand out compared to the current situation. Subsequently, you need to set targets and long-term goals, ${ }^{13}$ which could be done within your own CTT as well as on a larger scale within a group of multiple CTTs in your hospital that are confronted with the same task. The educational board meetings could be a valuable platform to develop these goals as well as discuss them on a regular basis. ${ }^{22}$

\section{Management Support And Leadership}

It is important to realize that managing change is not the same as leading it. The former means keeping the whole change process under control, while the latter means driving the change. In other words, leaders create a vision and determine what strategies are needed to achieve this vision, while managers develop plans and timetables to implement the strategy while keeping an eye on budgets as 
well. ${ }^{13,28}$ Yet despite their different functions, they are not contradictory but rather complementary to each other. ${ }^{28}$

It is important to realize that dealing with change is a collegial endeavor. It is teamwork and all team members have the opportunity to take a share and be a "leader". ${ }^{13,28}$ Within CTTs, program directors are usually the formal leaders of change. ${ }^{5,24}$ However, leaders as such do not need a formal title to lead. ${ }^{29}$ Among others, leadership entails stepping forward, collaborating as well as practicing followership, ie, making it possible for the most appropriate colleagues to take charge within a given team in a particular context. ${ }^{29}$ Indeed, a strong guiding coalition, as Kotter calls it, is a leading coalition that represents all different professionals involved. When implementing change, a strong guiding coalition with the right level of trust and a shared objective is always needed. ${ }^{13}$

Besides the guiding coalition, the educational board should be included in planning and monitoring the implementation process. This will show the members of CTTs that the educational board is committed early on. Furthermore, it will provide the program director with a platform for discussion with peers. Additionally, involvement of the educational board will ensure program deliverables and desired goals are aligned at a higher organizational level as well. ${ }^{7}$

\section{Staff Culture}

The crucial element to teamwork is a common goal. Only when team members have a deep desire to achieve the same objective does real teamwork become feasible. ${ }^{13}$ For instance, this common goal could be a commitment to excellence, a real desire to make specialty training perform at the highest level possible. Trust is vital in creating a shared objective. Among others, trust can be created by making sure the change is a topic in regular team meetings in which the input from your team members is appreciated..$^{7,13,30}$

Teams with a shared goal, mutual support and who create opportunities for participation and a common value that the input from all its members is important, are more likely to develop a sense of collectivity. ${ }^{30}$ CTTs who are able to exert high-quality teamwork are better able to make a proposed change valuable for their local context by creating strong ownership within the team. ${ }^{5-7,24,31}$ Thereby, it is important to be able to learn collaboratively, ie, building on the existing knowledge and skills base of the team, learning from mistakes, and being able to evaluate and modify the original plans. ${ }^{7,30}$
Defining the social networks within the team could also be very helpful. Medical doctors tend to operate in informal horizontal networks which are more effective in spreading peer pressure and reframing of meaning. On the other hand, formal vertical networks, are more effective for cascading information. ${ }^{7}$ Furthermore, as already mentioned earlier, the meaning of an innovation is socially constructed. Strong intra-organizational networks, such as medical doctors in management networks and vice versa as well as interprofessional teamwork, can help to facilitate this process. ${ }^{7,26}$

\section{The Formal Leader}

Leadership may be helpful in encouraging team members to break out of their daily routines. ${ }^{7}$ As the formal leader of educational change, ${ }^{5,24}$ program directors need to empower their colleagues to implement change. This could be done by defining clear roles and responsibilities as well as by ensuring the necessary resources are available. ${ }^{7,13,27}$ Furthermore, program directors who are able to gain an insight into the attitudes of the other team members, such as an active, passive, critical or non-critical stance, are better capable to lead the team. ${ }^{30}$

As a leader, it is not only important to gain an insight into the attitudes of the other team members but also involves the ability to self-reflect on one's own attitude. Leadership can come in many forms and a leader's mindset shapes the way his or her leadership is exerted. ${ }^{32}$ Being aware of one's own leadership style will help to adapt it when necessary. ${ }^{30}$ Leadership can also be learned or improved in leadership courses as well as in communities of peers. This will help program directors to look at their own context from different angles and to discover alternative ways to shape their leadership within their own setting. ${ }^{30}$ Again, the educational board could be a platform for the program director to share experiences and learn from each other.

Independent of your leadership style, you need to lead by example. Behavior that is inconsistent of that what is asked form others, overwhelms any other form of communication. ${ }^{13}$ And again, listen to the crowd. Two-way communication is essential to receive feedback as well as to ensure a sense of ownership, commitment and involvement with your colleagues during a change effort. ${ }^{13,22}$

\section{Involvement}

Creating a sense of involvement, or commitment, among team members is one of the most important factors in a 
change process. ${ }^{25,33}$ Commitment can be seen as a force or mind-set that binds an individual to a course of action that is of relevance to the successful implementation of change. ${ }^{33}$ Commitment can be increased when team members feel empowered to change. ${ }^{13}$ First of all, those involved should have the feeling their input is valued and listened to. ${ }^{7,22}$ This can be done by tailoring the implementation process to the needs of those involved ${ }^{7,13,27}$ as well as by structurally evaluating the change process and build on it. ${ }^{22}$ Open communication will also help to create a sense of commitment by enhancing the ability to share opinions and views, to learn together, and to sustain motivation. ${ }^{30,34}$ Furthermore, create dedicated time for change by, eg, adjusting workflows to align with the common vision when needed and building on your teams' expertise. ${ }^{13,22}$ The latter can be done by support networking with peers or other CTTs and by creating opportunities for training or conference leave when relevant for the change process. ${ }^{22}$

Again, communication is vital. Provide accurate and timely information about the impact of a change and its implementation process by using different forums such as team meetings and memos. ${ }^{7,13,22}$ Additionally, it is important to realize that effective information transferal does not happen overnight; it takes a lot of repetition, especially in a time-constraint environment such as health care. ${ }^{13}$

\section{Project Resources}

Resources include multiple factors such as time, money, knowledge and skills, but also structure and attitudes. ${ }^{7,13}$ Before a change is implemented it is crucial to think about what new behavior, skills and attitudes will be needed in the new situation. This needs to be compared with the existing knowledge and skills base of the CTT, after which it can be determined whether additional training or support is needed. ${ }^{13,22}$ It is important to bear in mind that team-based training as opposed to individual training might also enhance the sense of shared commitment and ownership. ${ }^{7,34}$

Improving the feasibility and workability of innovations is also part of this process. ${ }^{6,7,22}$ For instance, you decide you want to include a moment of direct observation of trainees during their consultations once a week. Then you need to ensure all team members are aware of the desired competencies of trainees as well as being competent themselves in providing feedback on those competencies. Additionally, more structural adjustments include incorporating extra time for observation and feedback in consultation schedules.

\section{Clarity Of Mission And Goals}

Vision is an aspirational picture of what your CTT would like to achieve or accomplish in the future and why the team should strive to create that picture. In other words, a vision is something to be pursued. A clear vision serves three purposes. First, it acts as a filter to separate what is important from what is not. Second, it motivates action that is not necessarily in people's short-term self-interest but subserves a greater good. And last, it helps to align different people and coordinate their actions. ${ }^{13}$

Among others, an effective vision is desirable, feasible and focused. An effective vision should comprise realistic goals and be clear enough to provide guidance. $^{13,23}$ However, above all, it should have an emotional appeal. ${ }^{13,35}$ For instance, to strive for being the best or most desired placement for trainees to learn a certain skill. When creating a vision on how a CTT could stand out in the future, you should always take the balance of costs and benefits of the entire group into account. Therefore, the development of vision is a delicate task that requires time and teamwork. ${ }^{7,22,23}$

\section{The Implementation Plan}

Planning the implementation of a change involves providing a clear timeframe, determine responsibilities within the team and establish explicit goals in the short as well as the long run. ${ }^{6,13}$ Planning for short-term wins is necessary, as short-term wins will help fine-tune vision and strategies, help to justify short-term costs involved and build morale and motivation. ${ }^{13}$ Furthermore, identify possible communication channels to use. ${ }^{7}$ It is also important to incorporate rigorous evaluation into the implementation process. This will help to identify any possible hurdles and enable you to modify your strategy in a timely fashion. ${ }^{22}$ Additionally, it will ensure you monitor whether the defined goals are reached within the desired timeframe. ${ }^{27}$

However, making an implementation plan not only involves providing timelines and evaluation plans.

It also entails improving the feasibility of a change. For instance, by breaking down the innovation into more manageable parts, the perceived complexity of a change process can be decreased. ${ }^{6,7}$

\section{General Remarks}

It goes without saying that implementing change takes time and requires patience. Do not expect a clean road to victory but rather an organic process including positive 
surprises and setbacks. Try to stay focused and keep monitoring any adjustments made to the innovation itself or the implementation process. This is particularly important, since the composition of a CTT may vary quickly, particularly because trainees tend to stay within the same department only for a limited amount of time. Furthermore, different strategies might be needed during different phases of the implementation process. $^{23}$ Therefore, when interpreting STORC it is always important to consider the phase of change you are in. Additionally, the educational systems itself should also be taken into account. Diversity in curriculum structures across teaching sites such as longitudinal programs versus rotation-based programs, as well as differences in health systems, could bring forward other needs when implementing the same change at different settings. ${ }^{2}$ Not surprisingly, within these different educational settings, one should also be aware of the influence of the organizational culture which could differ between countries, between organizations within countries and even between departments within the same organization. ${ }^{2,36}$

As mentioned earlier, this practical guide aims to help bridge the gap between theory in practice. To further enhance this effort, clinical teaching teams should be encouraged to demonstrate which change models were used in their educational settings, and share their best practices as well as the hurdles they were faced with in, in order for others to learn from. Second, further empirical study should help to strengthen the recommendations given in this practical guide. One format to do so would be to study a specific strategy for change in a real change setting using the methodology of action research. By using this format, multiple change strategies could be investigated, including ORC as described in this practical guide.

\section{To Conclude}

This practical guide aims to provide clinical teaching teams a helping hand in change processes by offering an insight into the different elements of readiness for change as well as by suggesting practical solutions when problems arise. The importance of shared commitment and leadership was emphasized, whether or not titled positions are hold. Above all, change is a team effort and requires collaborative learning. The more a CTT is able to systematically identify, interpret and share new knowledge, to link it to the existing knowledge base and to subsequently put it to appropriate use, the better it will be able to anticipate on the continuously changing environment.

\section{Acknowledgements}

We would like to thank Ineke Olsthoorn for her editing assistance.

\section{Disclosure}

The authors declare that they have no competing interests in this work.

\section{References}

1. Consoli D, Mina A. An evolutionary perspective on health innovation systems. J Evol Econ. 2009;19(2):297-319. doi:10.1007/s00191-0080127-3

2. Bank L, Jippes M, Scherpbier AJJA, Scheele F. Change management support in postgraduate medical education: a change for the better. In: Medical and Surgical Education - Past, Present and Future. Georgios Tsoulfas, editor. 2018

3. Graham ID, Logan J, Harrison MB, et al. Lost in knowledge translation: time for a map? J Contin Educ Health Prof. 2006;26(1):13-24. doi:10.1002/chp.47

4. Onyura B, Légaré F, Baker L, et al. Affordances of knowledge translation in medical education. Acad Med. 2014;90(4):518-524. doi:10.1097/ACM.0000000000000590

5. Bank L, Jippes M, Leppink J, et al. Are they ready? Organizational readiness for change among clinical teaching teams. Adv Med Educ Pract. 2017;8:807-815. doi:10.2147/AMEP.S146021

6. Jippes E, Van Luijk SJ, Pols J, Achterkamp MC, Brand PLP, Van Engelen JML. Facilitators and barriers to a nationwide implementation of competency-based postgraduate medical curricula: a qualitative study. Med Teach. 2012;34:e589-602. doi:10.3109/0142159X. 2012.670325

7. Greenhalgh T, Robert G, Macfarlane F, Bate P, Kyriakidou O. Diffusion of innovations in service organizations: systematic review and recommendations. Milbank Q. 2004;82(4):581-629. doi:10.1111/ milq.2004.82.issue-4

8. Damschroder LJ, Aron DC, Keith RE, Kirsh SR, Alexander JA, Lowery JC. Fostering implementation of health services research findings into practice: a consolidated framework for advancing implementation science. Implement Sci. 2009;4(1). doi:10.1186/1748-5908-4-50

9. Bank L, Jippes M, Leppink J, et al. Specialty Training's Organizational Readiness for curriculum Change (STORC): validation of a questionnaire. Adv Med Educ Pract. 2018;9:75-83. doi:10. 2147/AMEP.S146018

10. Bank L, Jippes M, Van Luijk S, den Rooyen C, Scherpbier A, Scheele F. Specialty Training's Organizational Readiness for curriculum Change (STORC): development of a questionnaire in a Delphi study. BMC Med Educ. 2015;15:127. doi:10.1186/s12909-015-0408-0

11. Weiner BJ. A theory of organizational readiness for change. Implement Sci. 2009;4(1). doi:10.1186/1748-5908-4-67

12. Holt DT, Helfrich CD, Hall CG, Weiner BJ. Are you ready? How health professionals can comprehensively conceptualize readiness for change. J Gen Intern Med. 2010;25(Suppl S1):50-55. doi:10.1007/ s11606-009-1112-8

13. Kotter JP. Leading Change. Boston, MA: Harvard Business Review Press; 2012.

14. Weiner BJ, Amick H, Lee SYD. Review: conceptualization and measurement of organizational readiness for change. A review of the literature in health services research and other fields. Med Care Res Rev. 2008;65(4):379-436. doi:10.1177/1077558708317802

15. Shea CM, Jacobs SR, Esserman DA, Bruce K, Weiner BJ. Organizational readiness for implementing change: a psychometric assessment of a new measure. Implement Sci. 2014;9(1). doi:10.1186/ 1748-5908-9-7 
16. Scheele F, Van Luijk S, Mulder H, et al. Is the modernisation of postgraduate medical training in the Netherlands successful? Views of the NVMO Special Interest Group on Postgraduate Medical Education. Med Teach. 2014;36:116-120. doi:10.3109/0142159X. 2013.849333

17. Chou S, Cole G, McLaughlin K, Lockyer J. CanMEDS evaluation in Canadian postgraduate training programmes: tools used and programme director satisfaction. Med Educ. 2008;42:879-886. doi:10. 1111/med.2008.42.issue-9

18. Ringsted C, Hansen TL, Davis D, Scherpbier A. Are some of the challenging aspects of the CanMEDS roles valid outside Canada? Med Educ. 2006;40:807-815. doi:10.1111/med.2006.40.issue-8

19. Hawkins RE, Welcher CM, Holmboe ES, et al. Implementation of competency-based medical education: are we addressing the concerns and challenges? Med Educ. 2015;49(11):1086-1102. doi:10.1111/ medu.2015.49.issue-11

20. Plsek PE, Greenhalgh T. Complexity science: the challenge of complexity in health care. BMJ. 2001;323(7313):625-628. doi:10.1136/ bmj.323.7313.625

21. Lewin K, Lewin GW, Cartwright D; Association AP. Resolving Social Conflicts: Selected Papers on Group Dynamics. Washington, DC: American Psychological Association; 1997.

22. Schultz K, Griffiths J. Implementing competency-based medical education in a postgraduate family medicine residency training program: A stepwise approach, facilitating factors, and processes or steps that would have been helpful. Acad Med. 2016;91(5):685-689. doi:10.1097/ACM.0000000000001066

23. Cohen DS. The Heart of Change Field Guide : Tools and Tactics for Leading Change in Your Organization. Boston, MA: Harvard Business School Press; 2009.

24. Bank L, Jippes M, Van Rossum TR, den Rooyen C, Scherpbier A, Scheele F. How clinical teaching teams deal with educational change: 'we just do it.'. BMC Med Educ. 2019;19. doi:10.1186/s12909-019-1815-4

25. Armenakis AA, Harris SG. Crafting a change message to create transformational readiness. J Organ Chang Manag. 2002;15 (2):169-183. doi:10.1108/09534810210423080
26. Ferlie E, Gabbay J, Fitzgerald L, Locock L, Dopson S. Evidencebased medicine and organisational change: an overview of some recent qualitative research. In: Ashburner L, editor. Organisational Behaviour and Organisational Studies in Health Care: Reflections on the Future. Palgrave Macmillan; 2001:18-42.

27. Rogers EM. Diffusion of Innovation. New York: The Free Press; 2003.

28. Ahn MJ, Adamson JSA, Dornbusch D. From leaders to leadership: managing change. J Leadersh Organ Stud. 2007;10(4):112-123. doi:10.1177/107179190401000409

29. Dath D, Chan M, Abbott C. CanMEDS 2015: from manager to leader. $R$ Coll Physicians Surg Canada. 2015:1-9.

30. Slootweg IA, Van Der Vleuten C, Jan Heineman M, Scherpbier A, Lombarts KMJMH. Program directors in their role as leaders of teaching teams in residency training. Med Teach. 2014;36 (12):1073-1079. doi:10.3109/0142159X.2014.923561

31. Bassett-Jones N, Lloyd GC. Does Herzberg's motivation theory have staying power? J Manag Dev. 2005;24(10):929-943. doi:10.1108/ 02621710510627064

32. Bolman LG, Deal TE. Leadership and management effectiveness: A multi-frame, multi-sector analysis. HRM Hum Resour Manag. 1991;30(4):509-534. doi:10.1002/hrm.3930300406

33. Herscovitch L, Meyer J. Commitment to organizational change: extension of a three-component model. J Appl Psychol. 2002;87 (3):474-487. doi:10.1037/0021-9010.87.3.474

34. Majmudar A, Jain AK, Chaudry J, Schwartz RW. High-performance teams and the physician leader: an overview. J Surg Educ. 2010;67 (4):205-209. doi:10.1016/j.jsurg.2010.06.002

35. Fox S, Amichai-Hamburger Y, Evans EA. The power of emotional appeals in promoting organizational change programs [and Executive Commentary]. Acad Manag Exec. 2001;15(4):84-95.

36. Ingersoll G, Kirsch J, Ehrlich Merk S, Lightfoot J. Relationship of organizational culture and readiness for change to employee commitment to the organization. J Nurs Adm. 2000;30(1):11-20. doi:10.10 97/00005110-200001000-00004
Advances in Medical Education and Practice

\section{Publish your work in this journal}

Advances in Medical Education and Practice is an international, peerreviewed, open access journal that aims to present and publish research on Medical Education covering medical, dental, nursing and allied health care professional education. The journal covers undergraduate education, postgraduate training and continuing medical education including emerging trends and innovative models linking education, research, and health care services. The manuscript management system is completely online and includes a very quick and fair peer-review system. Visit http://www.dovepress.com/testimonials.php to read real quotes from published authors. 